\title{
Colon Cancer by AJCC v7 Stage
}

National Cancer Institute

\section{Source}

National Cancer Institute. Colon Cancer by AJCC v7 Stage. NCI Thesaurus. Code C91224.

A term that refers to the staging of colon carcinoma according to the American Joint Committee on Cancer, 7 th edition. 